\title{
Leaving IJH: joining to fly
}

\author{
Toshio Kitamura $^{1}$ - Akifumi Takaori-Kondo ${ }^{2}$
}

Received: 4 November 2016 / Accepted: 4 November 2016 / Published online: 5 December 2016

(c) The Japanese Society of Hematology 2016

\section{Leaving IJH by Toshio Kitamura, the former Editor}

In 2012, I inherited the position of Editor-in-Chief of International Journal of Hematology (IJH) from Dr. Toshio Suda. Building on his strong legacy, the journal has continued to make new strides during my tenure, which saw the impact factor IF from 1.268 (2011) to 1.846 (2015). In 2014 , the journal recorded its highest ever impact factor of 1.918. Thanks in particular to the contributions of our Associate Guest Editors, our review series, "Progress in Hematology" continues to attract the attention of a broad readership in the hematology field, as evidenced by the high numbers of downloads and citations. More importantly, citations of original articles have also increased from 1.23 (2011) to 1.65 (2015), a clear indicator of continuing improvement in the quality of the original articles published in IJH and the journal's ever-broader impact in the field. From this year, the journal will change to an onlineonly journal, making a new stage for IJH.

Now at the end of my term as Editor-in-Chief, I would like to begin by sincerely thanking all the Associate Editors, lead reviewers, and reviewers for their wonderful support. Without their dedicated help, my editorial work would truly have not been possible. Their comments and decisions in the review process have always been timely and fair. It

Toshio Kitamura

kitamura@ims.u-tokyo.ac.jp

Akifumi Takaori-Kondo

atakaori@kuhp.kyoto-u.ac.jp

1 Division of Cellular Therapy, The Institute of Medical Science, The University of Tokyo, Tokyo, Japan

2 Department of Hematology and Oncology, Graduate School of Medicine and Faculty of Medicine, Kyoto University, Kyoto, Japan is not easy to do voluntary work at such a consistently high standard of quality while dealing with their busy schedules of physicians or researchers, but I have always been deeply impressed with the commitment and strong cooperation of associate editors and reviewers. I must take this opportunity to also thank Ms. Makiko Oonuma and the Japan Society of Hematology for their support and understanding in my editorial role over the past 4 years. Thanks in large part to Makiko's tremendous support, I have very much enjoyed my time as Editor-in-Chief. Finally, I would like to express my sincere appreciation to all the authors around the world who have chosen to submit their articles to IJH.

Now I am resigning the Editor position, which will be succeeded by Dr. Akifumi Takaori-Kondo, an excellent clinical scientist and my close friend. I will remain as an Associate Editor for a while to assist Dr. Takaori in further enhancing the journal in our sincere hope that IJH will continue to progress toward becoming one of the leading journals in the hematology field.

Joining to fly

Akifumi Takaori-Kondo, current IJH Editor-in-Chief

Starting from the November issue, I have taken on the duties of Editor-in-Chief of the International Journal of Hematology, taking the baton from Dr. Toshio Kitamura. I sincerely thank Dr. Kitamura and all those who have been serving this journal for their tremendous efforts to make the journal a success. As Dr. Kitamura noted above, during his stint as chief editor, IJH achieved marked progress in the quality and impact of its content, and I am truly honored to become Editor-in-Chief of this outstanding journal. As you may know, internationalization is now a central goal for the Japanese Society of Hematology, and I believe IJH should play a key role and lead the way in these efforts. To that end, we will continue to seek to attract submissions 
of high-quality and high-impact articles from around the world, and to publish as many as possible in a timely fashion. During my time as Editor-in-Chief, I will make every effort to take the IJH to new achievements and wider recognition as a premier hematology journal. I also look forward to the future cooperation of all the people serving the journal in various capacities, such as Associate Editors, lead reviewers, reviewers, and, of course, authors submitting their interesting work to IJH. I hope that IJH will continue to progress to fly high and build on its history of contribution to the hematology field. 